\title{
COMÉRCIO, REVITALIZAÇÃO URBANA E SUSTENTABILIDADE. ENSINAMENTOS DA EXPERIÊNCIA JAPONESA
}

CARlos José Lopes BALSAS ${ }^{1}$

\begin{abstract}
Resumo - O comércio urbano nas cidades Japonesas tem passado por períodos de grande transformação com o aparecimento recente de novos formatos comerciais e o declínio do pequeno comércio nas áreas centrais. As tendências de gestão urbana dos centros citadinos têm-se mostrado um tanto limitadas nos seus resultados. O objectivo deste trabalho é analisar a evolução recente das experiências de gestão e revitalização urbana e identificar um conjunto de ilações que possam ser úteis aos interessados pelo tema. $\mathrm{O}$ argumento principal é que as tendências de adopção de mecanismos e boas práticas estrangeiras, mais do que contribuírem para inverter situações de declínio urbano, têm-se mostrado algo inadequadas, em grande parte devido à ineficácia da articulação entre os poderes públicos e a sociedade civil. Parece, no entanto, que existem alternativas em abordagens de coesão socioeconómica à escala local e em operações integradas de revitalização urbana sustentável.
\end{abstract}

Palavras-chave: Comércio, urbanismo comercial, revitalização urbana, Japão.

Abstract - RETAIL, URBAN REVITALISATION AND SUSTAINABILITY. LESSONS FROM THE JAPANESE EXPERIENCE. Urban retail in Japanese cities has undergone important transformations as a result of new commercial formats and the decline of traditional retail establishments in central areas. The results of trends in the urban management of city centres have proven somewhat limited. The primary aim of this paper is to analyse the evolution of recent experiences of urban revitalisation and management and to identify a set of results that can be used by those still unaware of the Japanese reality. The argument is that the tendency to adopt foreign best practices has been inadequate, mainly due to problems of articulation between public powers and the civil society. Alternatives seem to exist in cohesive socio-economic activities at the local scale and in integrated operations of sustainable urban revitalisation.

Keywords: Retail, commercial urbanism, urban revitalization, Japan.

Résumé - COMMERCE, REVITALISATION URBAINE ET DURABILITÉ. LES ENSEIGNEMENTS DE L'EXPÉRIENCE JAPONAISE. Le commerce urbain dans les villes japonaises a

Recebido: Abril 2014. Aceite: Novembro 2014

1 Professor assistente no Departamento de Geografia e Planeamento, Universidade em Albany, Nova Iorque. E-mail: cbalsas@albany.edu 
connu des périodes de grande transformation, avec l'apparition récente de nouveaux formats commerciaux et le déclin du petit commerce dans les centres urbains. Les tentatives de gestion des aires centrales n'ont eu que des résultats limités. On a analysé l'évolution récente des expériences de gestion et de revitalisation urbaine, ce qui a permis d'identifier un certain nombre de remarques pouvant se révéler utiles. En particulier, on constate que l'adoption de mécanismes et de bonnes pratiques étrangères ne contribuent guère à inverser les tendances au déclin, parce qu'elles se montrent souvent inadéquates, surtout à cause d'une insuffisante corrélation entre l'action des pouvoirs publics et la société civile. Il parait cependant exister des alternatives basées sur la prise en compte de la cohésion socio-économique à l'échelle locale et la pratique intégrée de revitalisation urbaine durable

Mots-clés : Commerce, urbanisme commercial, régénération urbaine, Japon.

摘要 - 商业活动、城市复苏和可持续性 : 从日本经验所吸取的教训。随着新商业形式的出 现和中心区小商店的末落, 日本城市的商业模式经历了重大改变。城市规划试图对市中心施行的 管理效果强差人意。本文将分析城市管理和复苏试验的若干近期发展, 去为对此课题感兴趣者提 供一些启示。主要论点就是从外地输入机制和良方这个倾向很多时对改善城市衰落情况会无济于 事, 这主要是因为行政机矢与民间社会之间协调不善。然而, 在处理地方层次的社会经济凝聚力 方面, 以及在可持续城市复苏的整合行动方面, 似乎还存在其它选择。

矣键字：商业、商业城市主义、城市复苏、日本。

"People do not live only on bread but do not live without bread"

The Story of Poverty por Hajime Kawaki ${ }^{i}$

\section{INTRODUÇÃO}

O mercado comercial Japonês é bastante amplo. O proteccionismo económico por parte do governo central do Japão também não é novidade. Até bem recentemente, o Japão tinha a segunda maior economia mundial. A despesa com o consumo do agregado familiar per capita em 2009 era de cerca de 8,800 dólares (JETRO, 2009: 4). Em termos políticos, trata-se um país bastante conservador e que protege os seus interesses económicos, patrimoniais e culturais de modo muito inteligente.

A relação dos Portugueses com o Japão vem de longa data. Segundo a canção "Sol Nascente" de Teresa Salgueiro e Pedro Ayres Magalhães, os Portugueses foram os primeiros Europeus a chegar ao país no século XVI. Por outro lado Devezas e Rodrigues (2007) retratam o papel pioneiro dos Portugueses na globalização económica e nas trocas comerciais entre a China e o Japão durante o século XVI quando, devido a uma situação bélica, os Portugueses baseados em Macau lucraram económica e politicamente do comércio entre os dois países.

Durante quase dois séculos, depois de os Portugueses deixarem de ter o papel principal no quadro geopolítico da região, o Japão fechou a sua economia ao exterior até ao século XIX, iniciando as suas próprias tendências imperialistas na região Asiática, que terminaram com a destruição atómica das cidades de Hiroshima e Nagasáqui e o fim da Segunda Guerra Mundial.

Sustentada por grandes sacrifícios económicos e sociais, a reconstrução das cidades destruídas constituiu uma grande alavanca ao crescimento económico 
(Sorensen, 2002; Marcotullio, 2004). O poderio tecnológico, que foi habilmente exportado em produtos electrónicos, bem como o proteccionismo comercial interno, levaram a taxas de crescimento invejáveis até ao estrangulamento da bolha económica e da crise Asiática no início dos anos 90 (Castells, 1996; Hall, 1998). A crise financeira gerou muito crédito mal parado e a desaceleração forçada da economia, com implicações generalizadas não só para o país mas para a região envolvente.

Em termos internos, JETRO (2004) constata que, depois do colapso da economia, o consumo estagnou e as vendas diminuíram bastante. Por outro lado, a crise financeira abrandou o crescimento urbano e levou a experimentações com operações de revitalização urbana, sobretudo nos últimos 20 anos. O custo do solo aumentou em cerca de 200\%, entre 1985 e 1990, em algumas das maiores cidades Japonesas. Isto contribuiu para que fosse demasiado caro viver nos centros urbanos, sendo uma das consequências directas a descentralização e a suburbanização das cidades (Miyazawa, 2006). Registou-se também uma grande pressão externa, sobretudo dos EUA, para maior internacionalização da economia. Os grandes formatos comerciais aumentaram, em consequência de novas oportunidades de negócio, mas também como resultado da abertura do mercado Japonês ao capital estrangeiro. A nível demográfico registou-se uma tendência para o envelhecimento da população. Processos de desindustrialização também se observaram em determinadas zonas do país, levando a desestabilizações socioeconómicas e à necessidade de revitalizar zonas periurbanas e frentes ribeirinhas, agora relativamente apetecíveis sob o ponto de vista imobiliário (Sulkin, 2003).

Os centros de muitas cidades regionais ${ }^{\mathrm{ii}}$ - nomeadamente as suas áreas comerciais -, entraram em processos acelerados de declínio urbano e algumas operações de revitalização e gestão urbana tiveram resultados modestos e aquém das expectativas. Tal constatação confirma o argumento avançado por Sorensen, Marcotullio e Grant (2004) de que a eficácia da transferência de tecnologia (i.e., políticas públicas) sem a devida adaptação às circunstâncias locais e regionais é um mito profissional.

O objectivo deste trabalho é rever o contexto socioeconómico, legal e cultural que levou à criação de tais estruturas de revitalização urbana e tentar encontrar um conjunto de ilações que permitam substanciar práticas correntes em filosofias internacionais de intervenção urbanística, partindo da informação bibliográfica disponível. O argumento principal é que as tendências de adopção de mecanismos e boas práticas estrangeiras, mais do que contribuírem para inverter situações de declínio urbano, têm-se mostrado bastante desadequadas, devido sobretudo à ineficácia da articulação dos poderes públicos com a sociedade civil.

Esta investigação resultou do intercâmbio entre a Universidade Estadual do Arizona (ASU) e várias Universidades Japonesas (Universidade de Tóquio, TODAI, Universidade de Chiba, Instituto Tecnológico de Tóquio, entre outras), as quais contemplaram visitas técnicas do autor ao Japão, a sua participação em simpósios e conferências e entrevistas com especialistas de planeamento, arquitectura e membros da sociedade civiliii. 
Em Maio de 2005, o autor organizou um pequeno simpósio na Universidade Estadual do Arizona em Tempe, sobre o tema da Regeneração Urbana Sustentável (Balsas, 2005). Uma das principais preocupações do simpósio foi discutir e analisar até que ponto o Japão estava a ter sucesso na implementação de práticas urbanísticas sustentáveis e tentar encontrar alguns ensinamentos para a urbanização expansiva, típica do sudoeste dos Estados Unidos (Kobayashi, 2005). Directa ou indirectamente, a cidade de Phoenix, antes do início da crise financeira de 2007-2008, participou numa operação de regeneração urbana do seu centro, que de certo modo se enquadrou em práticas mais sustentáveis do que aquelas que historicamente tinham tido lugar na cidade e na sua área metropolitana.

Tendo como suporte essencial as políticas públicas, o presente texto está estruturado em quatro partes. Na secção II revêem-se as principais transformações sociais e urbanas na sociedade Japonesa, que levaram ao aparecimento da realidade comercial contemporânea. Em III faz-se uma caracterização sumária do urbanismo comercial enquanto prática de planeamento e gestão urbana. Na parte IV analisa-se o potencial da revitalização urbana e da sustentabilidade enquanto vectores estratégicos para a estruturação de intervenções urbanísticas. Em V dão-se exemplos de iniciativas de revitalização urbana, que permitem enquadrar as bases teóricas e administrativas em experiências específicas. Finalmente, na conclusão, apresentam-se ideias que possibilitem a promoção de cidades mais coesas e sustentáveis sob o ponto de vista do comércio urbano.

\section{TRANSFORMAÇÕES URBANAS, SOCIO-ECONÓMICAS E COMERCIAIS}

As cidades regionais Japonesas, sob o ponto de vista comercial, estão a experimentar o mesmo fenómeno que ocorreu noutras cidades do mundo desenvolvido (Gruen, 1964). Nessas cidades, com o aumento da suburbanização, as funções habitacionais, comerciais e de serviços deslocaram-se para as periferias e os idosos e outras pessoas com rendimentos relativamente mais baixos ficaram nos centros urbanos (Quin, 2002); por seu lado, o pequeno comércio envelheceu e perdeu competitividade.

Este fenómeno é bastante mais acentuado nas cidades de pequena e média dimensão. As grandes metrópoles como Tóquio, Osaka e Nagoia têm economias e dinâmicas adequadas à sua hierarquia no sistema urbano e populacional. A sua estrutura polinucleada, assente em redes de transportes, com primazia para os ferroviários, coloca-as num patamar diferenciado das suas congéneres de menor dimensão (Caballero e Tsukamoto, 2009).

O transporte ferroviário é um elemento estruturador importante do tecido urbano. As estações ferroviárias têm um papel fundamental na criação de grandes polaridades (Cybriwsky, 1993). Nas grandes metrópoles, as cidades têm centros financeiros e bairros bem individualizados e com identidades muito distintas. A densidade populacional é relativamente elevada e o dinamismo das áreas comerciais é 
assegurado pela grande concentração de estabelecimentos (Greenbie, 1988; Matsui et al., 2005). Assim, nas metrópoles com mais de 8 milhões de habitantes, como Tóquio, Osaka e Kanagawa, as vendas comerciais nos centros das cidades constituem cerca de $85 \%$ do total; nas cidades localizadas fora das áreas metropolitanas (com menos de 2 milhões de pessoas), cerca de $40 \%$ das vendas registam-se em lojas das periferias (Muraki, 2003).

As grandes cidades globais têm sido muito estudadas (Sassen, 2001), mas as cidades regionais são igualmente importantes, ou ainda mais, devido ao seu maior número e à sua capacidade agregadora em cada país (Yamashita, 2004). Enquanto o grande armazém comercial, denominado de "depato", nas imediações das estações de caminhos-de-ferro e em outras localizações urbanas, é um formato comercial muito comum (Matsushita, 2001), nas cidades de menores dimensões, o comércio é sobretudo de natureza familiar, independente e tradicional. Bi-Matsui (2009: 72) menciona um estudo, realizado em 2006, que identificou 59 lojas independentes para cada 4 lojas de cadeias nacionais em áreas comerciais urbanas.

Em 2000, o retalho gerava $55 \%$ do total do emprego no comércio, $12 \%$ do total do emprego no Japão e cerca de $5 \%$ do produto interno bruto (Grier, 2001: 4). Mas o número de centros comerciais aumentou consideravelmente nos últimos tempos, ainda que estes formatos estejam sujeitos a regulamentos específicos e até restritivos, sobretudo devido a intensas pressões de grupos de interesse do pequeno comércio.

Os Estados Unidos, através das conversações da Iniciativa dos Impedimentos Estruturais (IIE) que tiveram início em 1989, fizeram uma grande pressão para a remoção de restrições à abertura de grandes estabelecimentos comerciais e à entrada de grupos económicos estrangeiros no país (Abe, 1999). Isto foi, em certa medida, conseguido com a eliminação de competências municipais na área comercial e com entraves que as prefeituras colocaram à abertura de grandes estabelecimentos comerciais.

Esta tentativa de desregulamentação e de liberalização pode contribuir para acentuar as tendências de declínio dos centros das cidades, e sobretudo anular os investimentos realizados em prol da sua revitalização. Shibata (2008) lembra-nos que a economia neoliberal precisa de regras e de supervisão estatal, de modo a poder funcionar sem destruir mais-valias colectivas.

A cultura Japonesa está bem vincada nas características dos consumidores: preferência por alimentos frescos, exigência com a qualidade dos produtos e expectativas elevadas ao nível dos serviços prestados (Azuma e Fernie, 2001). Mas entre os consumidores mais jovens, principalmente nos subúrbios, nota-se uma tendência para fazer compras mais concentradas e com menos frequência (Garon e Maclachlan, 2006). A entrada das mulheres na força de trabalho alterou também os estilos de vida das famílias Japonesas. As marcas comerciais passaram a ter peso importante nas compras durante o boom económico (Haghirian e Toussaint, 2011).

Devido às altas densidades populacionais nos bairros citadinos, o modo habitual de deslocação para fazer compras era a pé ou de bicicleta. Com a ida para os 
subúrbios as deslocações passaram a ser feitas de automóvel. Contudo, cerca de 9,1 milhões de pessoas não possuem automóvel, e o comércio fica a mais de 500 metros das suas habitações (The Yomiuri Shimbun, 2012). Ainda segundo a mesma fonte, muitos dos centros urbanos estão a transformar-se em "desertos alimentares", tal como já aconteceu noutros países (Balsas, 2008).

É comum os comerciantes viverem no piso superior e terem os seus estabelecimentos no piso térreo, com abertura para a rua comercial ("shotengai") (Shelton, 1999). A popularidade deste formato comercial manteve-se até aos anos 90 (Seta, 2008) mas, quando o ciclo de crescimento económico abrandou, registou-se um decréscimo de vendas de cerca de $8 \%$, entre 1991 e 2002, com incidência relativamente grande no pequeno comércio. Verificou-se também uma diminuição de cerca de $7 \%$ do número total de lojas durante o mesmo período de tempo. Ocorreu ainda a tendência de aumento da área dos estabelecimentos comerciais iv .

Apesar disto, existia ainda um número elevado de pequenos comerciantes, principalmente no ramo alimentar ${ }^{v}$. Entre as principais razões para estas alterações, está o crescimento económico elevado nos anos 80 , a preferência por produtos frescos em lojas locais, um sistema de protecção do comércio a retalho e a existência de leis de controlo de abertura de grandes formatos comerciais iniciadas ainda antes da Segunda Guerra Mundial.

Segundo um relatório do Ministério da Economia, Comércio e Indústria, durante os anos 90 os salários mantiveram-se constantes, enquanto os custos com a educação, a saúde e os empréstimos bancários aumentaram; o poder de compra também diminuiu, o que levou à procura de produtos de mais baixo custo (JETRO, 2004). Uma consequência directa foi a redução das margens de lucro dos comerciantes, de modo a manterem-se competitivos sem perderem as suas quotas de mercado.

A entrada de empresas estrangeiras no mercado Nipónico data dos anos 70 e 80, inicialmente com marcas de luxo tais como Louis Vuitton e Hermès, depois marcas mais práticas e com preços moderados como Eddie Bauer e HMV; mais recentemente entraram cadeias de retalho como Costco, Carrefour e outras como WalMart e Tesco. Marcas como OfficeMax, Sephora e the Boots, acabaram por abandonar o mercado Japonês, devido a falta de preparação e incompreensão dos hábitos dos Japoneses ${ }^{\mathrm{vi}}$.

Existem discrepâncias entre o pequeno e o grande comércio e a tendência para a homogeneização das paisagens comerciais. Tem-se assistido ao encerramento de lojas em galerias comerciais e à abertura de centros comerciais nas periferias das cidades, com base em padrões de acessibilidade, sobretudo automóvel (fig. 1 a 3). Os supermercados sentiram aumento da concorrência, mas muitos deles adaptaram os seus horários de funcionamento mantendo-se alguns abertos 24 horas. As lojas de conveniência continuaram a aumentar, mas houve uma diminuição do número de vendas por cliente. 


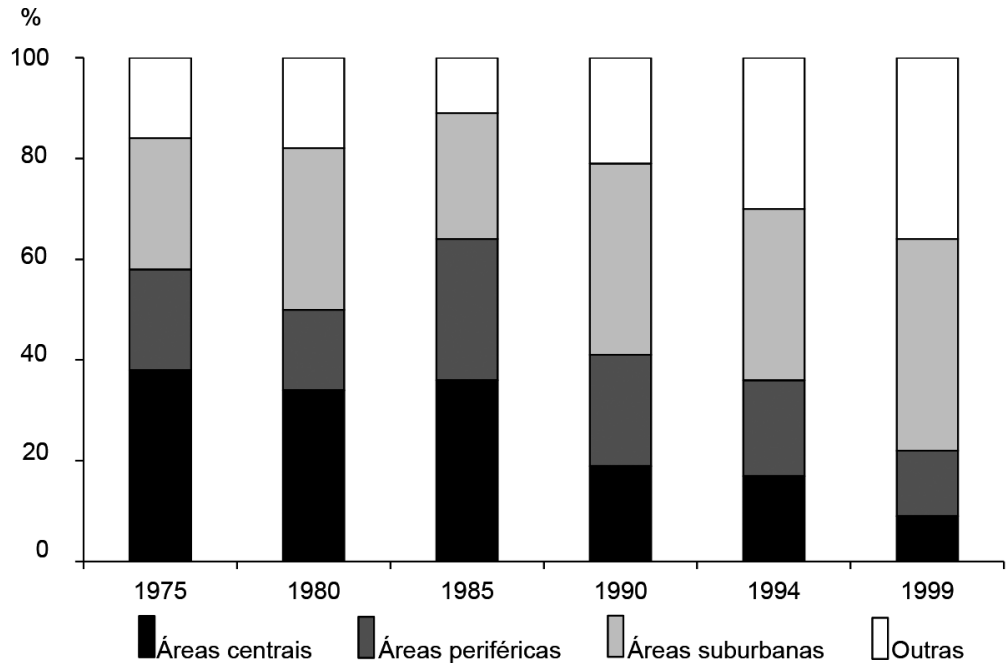

Fig. 1 - Localização de novos centros comerciais no Japão. Fig. 1 - Location of new shopping centres.

Fonte: Takami, 2006: 140

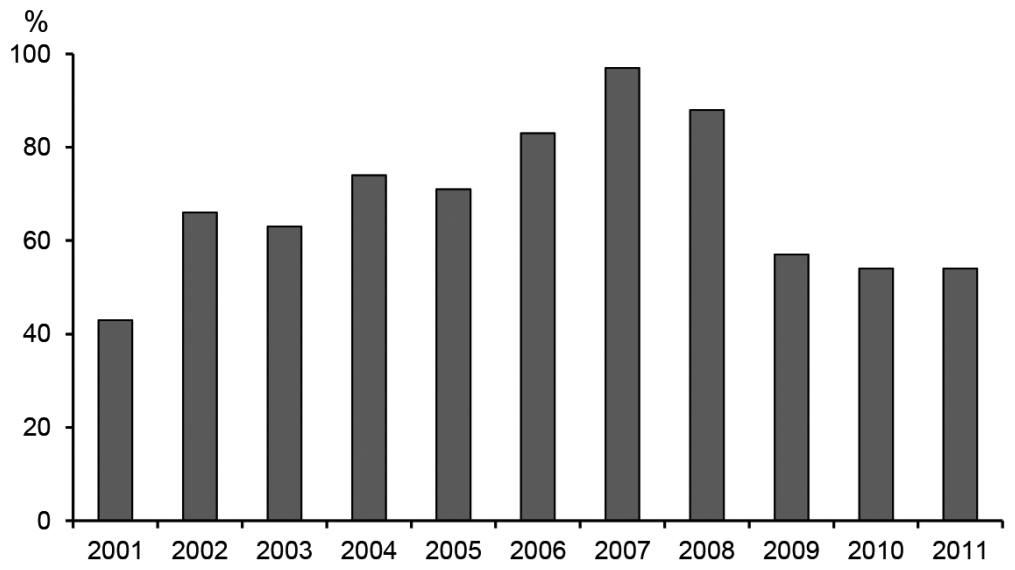

Fig. 2 - Número de novos centros comerciais no Japão.

Fig. 2 - Number of new shopping centres.

Fonte: http://www.jcsc.or.jp/ [acedido em 7 de Outubro de 2012] 


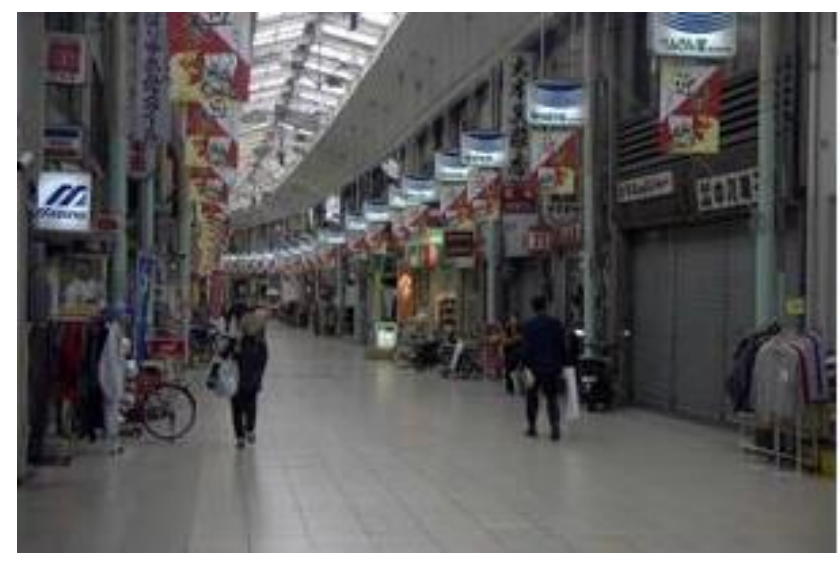

Fig. 3 - Galeria comercial em Onomichi.

Fig. 3 - Shopping arcade in Onomichi.

Autor, 2005.

Em 2002 existiam 2615 centros comerciais no Japão. Este número representava um aumento de $12 \%$ em relação ao ano anterior. Mais de 50 novos centros abriram em 2002. As principais lojas âncora eram constituídas por armazéns comerciais (equivalentes a hipermercados) e por supermercados. Com a grande escassez de solo nas grandes cidades encontram-se muitos centros comerciais subterrâneos.

Os efeitos da suburbanização são bem conhecidos e incluem o aumento da utilização do automóvel, congestionamento e poluição nos subúrbios, perda de ambiente suburbano natural e, ainda, reduções no acesso a lugares de compras por parte dos que não têm automóvel, ou não podem conduzir (Sorensen, 2004; Takami, 2006). Em 2011, segundo a Associação Japonesa de Centros Comerciais existiam no país 3090 centros comerciais $^{\text {vii }}$ que ocupavam 45 milhões de metros quadrados. $\mathrm{O}$ valor médio por piso era de 14789 metros. Devido a dinâmicas urbanas complexas, as parcelas de solo para construção de novos centros comerciais de dimensão significativa começou a escassear. Um formato também muito popular no Japão é o das lojas de conveniência.

\section{URBANISMO COMERCIAL}

O urbanismo comercial engloba as leis e as práticas urbanísticas e de regulamentação que influenciam a localização, a abertura e a utilização dos estabelecimentos de carácter comercial para a criação de cidades mais sustentáveis. No Japão há um conjunto de três leis que são frequentemente mencionadas como tendo um papel importante na paisagem comercial das cidades Japonesas. Estas leis ${ }^{\text {viii }}$ incluem: 1) a Lei dos Formatos Comerciais de Grande Porte (LFCGP) aplicada a estabelecimentos com mais de $1500 \mathrm{~m}^{2}$; 2) a Lei da Vitalização Urbana (LVU); e 
3) a Lei do Planeamento Urbano (LPU). Todas elas são revisões de leis mais antigas sobre as mesmas temáticas, que têm sido modificadas de acordo com critérios políticos, sociais e económicos. Upham (1993) descreve em detalhe a implementação conturbada da versão anterior da LFCGP, em vigor desde 1973, e conclui que os poderes públicos tiveram dificuldades em lidar com os interesses comerciais no que toca à abertura de novos estabelecimentos de grande porte devido ao lobby do pequeno comércio e do sector da distribuição.

A tentativa do governo central controlar o sector comercial já vem de longa data: remonta a 1937, quando se proibia a operação de um armazém comercial com mais de $1500 \mathrm{~m}^{2}$. Esta lei resultou de pressões políticas do pequeno comércio e de tentativas de redução de monopólios. Actualmente, o peso do governo central é menor do que há duas décadas mas ainda se faz sentir na supervisão da abertura de novas lojas de grande porte.

Segundo Grier (2001), a LFCGP de 1998 difere da legislação anterior em quatro pontos principais: 1) alterou o âmbito da regulamentação da protecção do pequeno comércio; 2) retirou alguma responsabilidade pela implementação da lei do governo central para o governo local; 3) proibiu o governo local de ter em conta as necessidades económicas das áreas envolventes às lojas comerciais; 4) permitiu ao governo local recomendar apenas pequenos ajustamentos nos estabelecimentos de grande porte, ao contrário da lei anterior que permitia que os municípios obrigassem os proprietários das grandes lojas a fazerem ajustamentos consideráveis, de modo a resolver potenciais problemas concorrenciais com o pequeno comércio.

De acordo com um relatório do Ministério da Economia, Comércio e Industria Japonês (JETRO, 2004: 37), em Junho de 2000 as lojas com mais de $1000 \mathrm{~m}^{2}$ estavam sujeitas a regulamentação. Era necessário recolher a opinião da comunidade local sobre o impacte da nova loja, incluindo aspectos como: trânsito, reciclagem, conveniência, prevenção do fogo, redução do ruído, gestão de resíduos e enquadramento na paisagem local.

Enquanto a lei anterior regulamentava a abertura de novas lojas de grande porte e colocava restrições económicas ao comércio da área de influência (dias de operação e horários), a nova versão da lei coloca restrições sociais de modo a proteger os estabelecimentos e o seu ambiente circundante e a criar comunidades urbanas sustentáveis, sem restringir directamente a competição.

A segunda lei mencionada (Lei da Vitalização Urbana - LVU) é importante na área do urbanismo comercial porque criou apoios financeiros para os municípios (re)vitalizarem os seus centros urbanos, sobretudo através de apoios financeiros com base em propostas (planos e estratégias) preparadas pelos próprios municípios e outras organizações de gestão urbana. Entre as actividades elegíveis encontram-se infra-estruturas comuns e operações de promoção e reestruturação económica. Em 2003 cerca de 600 municípios tinham desenvolvido um plano de revitalização de centro urbano. A Town Management Organization (TMO) de influência Europeia é o tipo de organização responsável pela implementação destes planos de melhoramentos dos centros (JETRO, 2004). Esta nova organização, baseada em parcerias 
criadas pelos principais interesses instalados nos centros urbanos, é caracterizada em detalhe na secção seguinte.

A lei da vitalização dos centros urbanos permite a colaboração com vários tipos de organizações: associação comercial e industrial, câmara do comércio e indústria, empresa semi-pública, corporação quási-pública, e várias organizações não-governamentais (ONG). A criação das TMO obrigava ao desenvolvimento de um plano de negócios e era técnica e financeiramente independente de outras entidades mas, para ser eficaz, requeria colaborações institucionais com outras entidades locais e regionais.

Por último, a Lei do Planeamento Urbano (LPU) introduziu alterações no zonamento do uso do solo e permitiu aos municípios criarem áreas específicas para determinados usos comerciais. De acordo com o sistema de planeamento, o solo pode ser dividido em três categorias principais segundo a sua localização em 1) áreas de planeamento urbano, 2) áreas quase de planeamento urbano, 3) exteriores a áreas de planeamento urbano. A primeira categoria pode ainda ser subdividida em áreas de promoção de urbanização e áreas de controlo de urbanização. É ainda possível aos municípios criarem zonas especiais sobrepostas (overlay district), por exemplo no caso de desenvolvimentos comerciais prioritários, ou de protecção ao pequeno comércio. Lojas com mais de $3000 \mathrm{~m}^{2}$ em áreas 'quase de planeamento urbano' também necessitam de licença de funcionamento.

Para além destas três leis principais, o governo central criou em 2006 uma directiva para complementar a lei dos formatos comerciais de grande porte, para tentar proibir a abertura nos subúrbios de centros comerciais com área superior a $10000 \mathrm{~m}^{2}$ $(K y o g o k u, 2006)^{\mathrm{ix}}$. Esta directiva foi inspirada na lógica Inglesa do town-centre first com uma hierarquização e alocação progressiva de solo urbanizável do centro para a periferia (JIJI Press, 2011). Infelizmente para alguns municípios, a lei não permite que a regulamentação local seja mais rígida do que a nacional.

Com a criação desta directiva, os TMO foram alargados para comissões e outras organizações de âmbito local passaram a poder integrar as operações de revitalização urbana com a possibilidade de partilha de conhecimentos técnicos e com vantagens resultantes de economia de escala. Cerca de 30\% dos 2239 municípios no Japão tinham realizado planos de revitalização urbana no âmbito de TMO por esta altura. As intervenções têm sido sobretudo de dois tipos: desenvolvimento urbano e promoção económica. Um dos benefícios desta directiva foi a identificação de mecanismos de análise dos potenciais impactos comerciais dos estabelecimentos. Apesar de tudo, devido ao elevado número de comerciantes nas áreas centrais e às diferentes prioridades pessoais, é relativamente difícil obter consensos que levem à plena revitalização dos centros urbanos.

\section{REVITALIZAÇÃO E GESTÃO URBANA}

A filosofia das organizações de gestão e revitalização urbana é baseada na tentativa de melhorar os centros urbanos e de os tornar mais resilientes ao aumento 
da competição criada pelos novos formatos comerciais. Os centros urbanos sempre tiveram um papel importante no desenvolvimento regional do Japão. O progresso rápido da motorização ${ }^{\mathrm{x}}$, a diversificação de estilos de vida, a migração da população para os subúrbios, a dispersão de centros de emprego e de serviços, o aumento do número de lojas devolutas, a falta de sucessores, a escassez de locais de estacionamento automóvel e a saída de lojas do centro para a periferia levaram a uma diminuição da atractividade do comércio localizado dentro do perímetro urbano. A sustentabilidade das cidades e a revitalização urbana tornaram-se assim preocupações de interesse nacional (JETRO, 2000; Sorensen, 2004).

Segundo Muraki (2003), o governo central criou um programa de revitalização urbana para tentar inverter as tendências de declínio urbano, com uma verba de cerca de um bilião de dólares Norte-Americanos, sobretudo para o período 1998-2006. Os fundos foram distribuídos com base em concursos públicos onde foi necessário submeter uma estratégia de gestão do centro e um programa de revitalização. Até 2003 cerca de 577 entidades locais tinham submetido propostas que incluíam acções de pavimentação, construção de melhoramentos urbanos, reforço de competências profissionais. Na mesma data, 268 organizações locais (TMO) tinham sido criadas com base em programas principalmente de associações comerciais (Muraki, 2003).

Há um leque abrangente de exemplos que podem ser categorizados em dois grandes grupos: 1) intervenções no edificado e em espaços públicos, 2) campanhas integradas de promoção do pequeno comércio e de reestruturação económica. Entre os primeiros, encontramos a renovação do edificado, a reconstrução de fachadas, redefinição de zonas comerciais, construção de centros comerciais e arcadas/galerias, obras de pavimentação, melhoramento das acessibilidades e das condições de locomoção para deficientes motores, estacionamento automóvel e medidas para reduzir o congestionamento.

Entre as medidas de promoção encontramos: cartão de fidelização de compras, entregas ao domicílio, utilização de lojas devolutas, campanhas de promoção de vendas, promoções para atrair novos comércios e novos clientes, trabalho em rede (networking), melhoramento da composição comercial, postos de atendimento ao público e de divulgação turística, promoção do comércio nas áreas centrais, campanhas de descontos, vários instrumentos de promoção e gestão comercial das áreas centrais, ninhos de empresas, promoção da identidade local e criação de 'lojas desafio' (challenge shop). Estas lojas são arrendadas a comerciantes, de modo a testar conceitos inovadores antes de eles correrem riscos maiores e fazerem investimentos mais avultados. Mas as TMO são também consideradas organizações importantes na revitalização de áreas atingidas por calamidades naturais, tais como tremores de terra (Beniya, s/d).

Entre os principais problemas com estas entidades de gestão urbana encontra-se a escassez de recursos humanos, a falta de verbas e dificuldades burocráticas, tais como negativismo por parte dos comerciantes, incompatibilidade entre visões locais, dificuldade em obter financiamentos adicionais, falta de conhecimentos técnicos e de informação relativa a métodos e estratégias comerciais e de serviços, assim como 
o desconhecimento de casos nacionais bem-sucedidos. Tudo isto tornou difícil a obtenção de consensos sobre os modos mais adequados de revitalizar os centros urbanos (Bi-Matsui, 2009).

Mas há alguns exemplos de TMO em que os líderes das comunidades tiveram um papel importante na revitalização urbana e na coordenação dos participantes. Segundo Seta (2008), há diferentes tipos de organizações que participam em actividades de revitalização de centros urbanos. Em geral, os comerciantes são sócios destas associações e muitas vezes pertencem a várias associações em simultâneo. Mas não é obrigatório ser membro para participar em actividades de revitalização urbana.

Em média, cerca de $80 \%$ dos comerciantes localizados num dado centro urbano são membros de uma associação comercial (Seta, 2008). Segundo o mesmo autor, muitos deles enriqueceram no centro da cidade e mudaram a residência para os subúrbios, mantendo a loja no centro. O centro passou a ser quase exclusivamente um lugar de comércio e não mais um lugar para habitar. Em muitos destes casos, como os proprietários não precisam financeiramente do rendimento do comércio, preferem manter a loja fechada a vendê-la.

Uma situação diferente tem a ver com a escala e a própria natureza dos centros urbanos. Os centros das cidades Japonesas de escala regional são muito densos, com habitações uni e multifamiliares feitas de diversos materiais (incluindo madeira), e de elevada vulnerabilidade a incêndios e a catástrofes naturais. Assim, muitas das operações de revitalização urbana propõem esquemas de ajustamento do solo e grandes operações fundiárias de reparcelamento e de reurbanização (Onishi, 1994; Seta, 2008).

Este processo, que ocorreu na cidade de Fukaya, e os desafios que se colocaram à comunidade local foram examinados por Koizumi (2004) e por Murayama (2005), que concluíram que as operações são bastante complexas, devido não só aos interesses fundiários, mas também devido às alterações urbanas e sociais que provocam. Para além de serem oportunidades para discussão de opções colectivas, servem ainda para encontrar modos de projectar novos destinos para os centros urbanos. Relativamente mais simples, por não envolverem alterações fundiárias, são os encerramentos de espaços comerciais ou de outros edifícios de volumetria elevada no centro e em que o município tenta reforçar a centralidade com usos mistos, que são promovidos por uma cooperativa comunitária.

Em relação às operações de revitalização urbana, Muraki (2003) formulou três conclusões principais: 1) a revitalização urbana deve ser abrangente e ir além da área de comércio; a obtenção de consensos é importante e o plano estratégico deve permitir repensar as funções do centro e trazer todos os interessados para a discussão de alternativas, 2) há necessidade de coordenar as actividades de revitalização urbana com outras áreas de desenvolvimento e planeamento urbanístico, 3) é preciso melhorar a integração e partilha de dados, e a monitorização e acompanhamento das actividades de gestão.

Uma diferença fundamental identificada por Seta (2008) é que no centro comercial as relações são hierárquicas, enquanto na rua comercial elas são geralmente paralelas, uma vez que a maioria dos proprietários está ao mesmo nível em termos 
de representação associativa. Isto traz algumas desvantagens, incluindo maior complexidade, no que concerne ao planeamento e execução dos projectos de urbanismo comercial, mas serve para justificar a existência de um gestor de centro urbano a tempo inteiro.

\section{ALGUMAS INICIATIVAS RECENTES}

O planeamento urbano no Japão é muito centralizado e de estilo (top-down) dirigista (Alden, 1984; Sorensen, 2002). Recentemente aponta-se para uma flexibilização desta prática e reforço dos movimentos associativos de origem local, do género machi-zukuri (Sorensen, Koizumi e Miyamoto, 2009). Evans (2002) descreve em pormenor o significado do conceito de machi-zukuri (planeamento de cariz comunitário) que contrasta com o rígido, e por vezes burocrático, toshi-keikaku (planeamento urbano). Segundo Evans, o machi-zukuri tem quatro características principais: 1) estímulo à participação pública, 2) ênfase na descentralização, 3) equilíbrio entre aspectos organizacionais e intervenções físicas, 4) intervenções graduais e faseadas no tempo, tipicamente de longo prazo (20 anos). Hein (2008) afirma que o significado do termo machi (bairro, vila) é importante para perceber a forma urbana de muitos bairros Japoneses e o significado do planeamento urbano.

No Japão há uma grande variedade de iniciativas de revitalização urbana que dependem dos promotores, da região em que se inserem e dos níveis de investimento envolvidos. Entre as principais iniciativas, encontram-se operações integradas de desenvolvimento urbano, cujo objectivo principal é a sustentabilidade enquanto orientação de política pública e referencial estratégico em comunidades de bairro (Sorensen, Marcotullio e Grant, 2004). O intuito fundamental é a promoção da renovação do edificado urbano e também a criação de um espírito associativo de base local e o reforço das identidades.

Carmona (2012) defende que preocupações com segurança, por vezes dúbias, estão a ser utilizadas para destruir bairros residenciais tradicionais, ruas estreitas e comércio de proximidade. O mesmo autor argumenta que a demolição de áreas urbanas é um exemplo da falta de consideração pelo urbanismo tradicional Japonês. Na mesma linha de argumentação, Sorensen (2009) garante que a partilha dos direitos de propriedade e a necessidade de reclamar gestão partilhada de espaços públicos e de desenvolvimento comunitário no estilo machi-zukuri tem sido uma opção eficaz no bairro de Yanaka na cidade de Tóquio.

Por seu lado, Hattori (2011) descreve o bairro de Shimokitazawa - também em Tóquio, com as suas ruas estreitas, comércio de base familiar, restaurantes, teatros e outros espaços culturais, no qual a atractividade entre as camadas jovens é bem vincada - como um exemplo marcante do conceito de habitabilidade sustentável. Nashima (1997) assegura que na impossibilidade de financiar todas as candidaturas com apoios governamentais, inicialmente o governo central utilizou uma lógica de cidades modelo, de modo a garantir exemplos-tipo para outras aglomerações urbanas. 
Tive oportunidade de confirmar muitas destas tendências em operações de revitalização urbana nas viagens que fiz ao Japão. Por exemplo, no bairro de Shibuya (fig. 4) participei em reuniões com representantes da comunidade local, e numa ronda pela área comercial com um conjunto de representantes da prefeitura, da associação comercial, e uma série de comerciantes e membros das forças policiais. O principal objectivo do Shibuya Center-Gai era semelhante ao Business Improvement District (BID) do Times Square em Nova Iorque, mas sem a obrigatoriedade de cobrança coerciva de taxas adicionais.

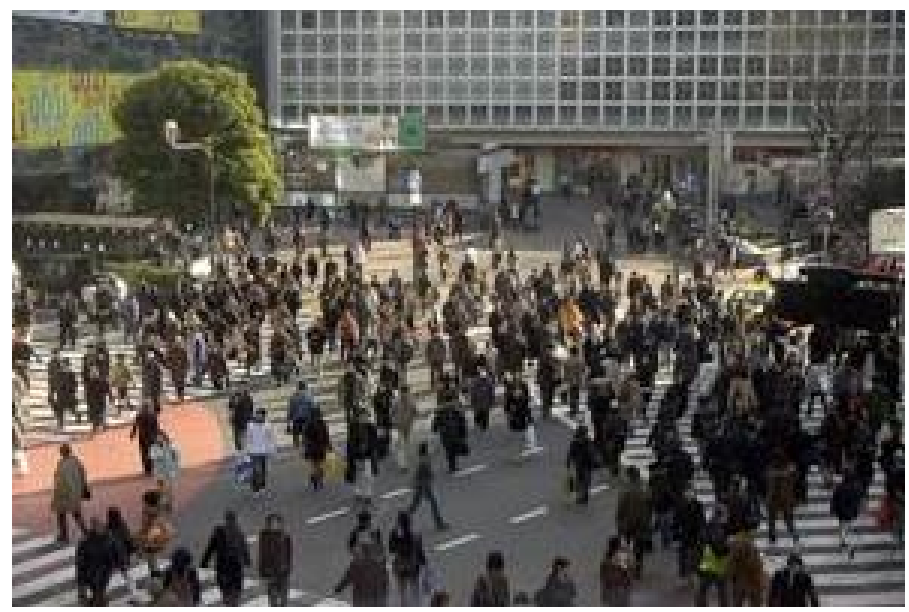

Fig. 4 - Área comercial de Shibuya em Tóquio.

Fig. 4-Commercial area of Shibuya in Tokyo.

Autor, 2005.

Em Sakura (fig. 5), visitei a área central da cidade, que fica a cerca de $65 \mathrm{~km}$ de Tóquio e participei em reuniões com membros da TMO. Pude constatar in loco as dificuldades para a implementação deste tipo de parceria de gestão urbana. Devido à relocalização de edifícios públicos (biblioteca e outros serviços) fora da área central e ao crescimento das áreas periféricas, muitos estabelecimentos comerciais ressentiram-se (cerca de $20 \%$ ) e foram obrigados a encerrar. Há esperanças de que a área do lazer e o turismo tragam alguma vitalidade à zona (Quin, 2002), uma vez que aí se localizam equipamentos culturais, como museus e outros edifícios de cariz tradicional, assim como uma "loja desafio". 


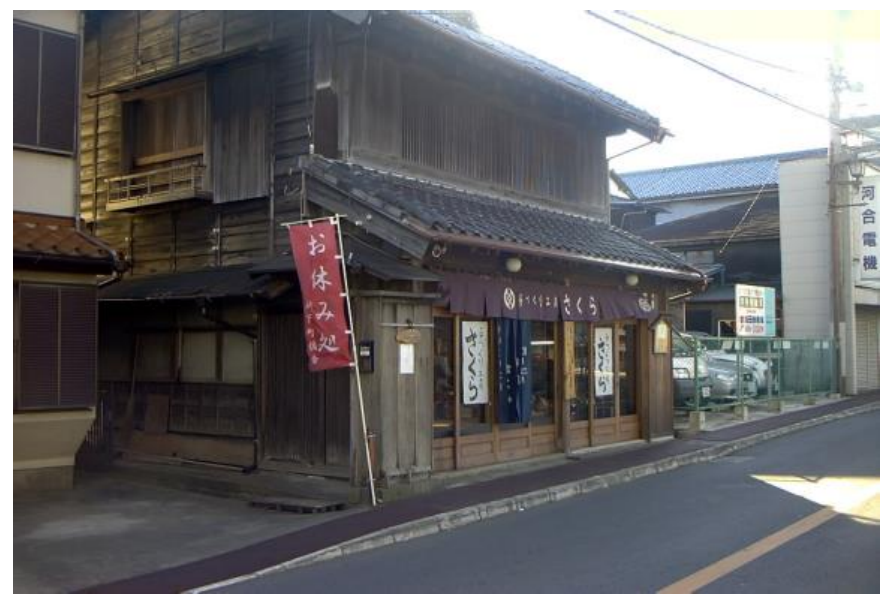

Fig. 5 - Rua comercial em Sakura.

Fig. 5 - Shopping street in Sakura.

Autor, 2005.

No bairro envolvente ao campo principal da Universidade de Tóquio, em Hongo, visitei uma área típica da cidade, singular nas suas tradições de vivências urbanas e culturais. O tecido urbano é compacto, muitas ruas são estreitas e sem trânsito automóvel, o comércio é de pequenas dimensões e os espaços públicos aparentavam ser muito bem geridos e com vivências colectivas bastante saudáveis e sustentáveis (fig. 6). Apesar de desconhecer a existência de projectos de planeamento urbanístico para este bairro, a sua vitalidade parecia augurar um bom futuro.

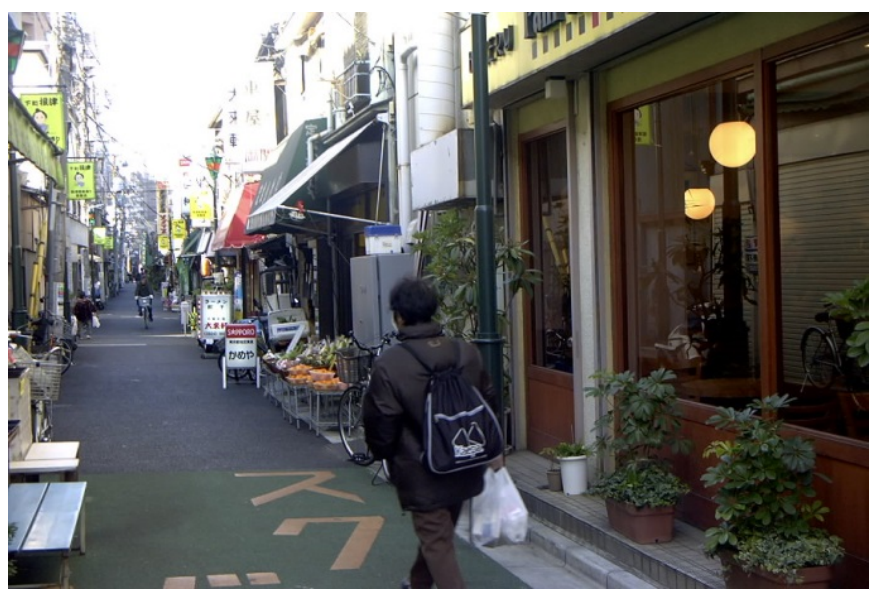

Fig. 6 - Bairro de Hongo em Tóquio.

Fig. 6-District of Hongo in Tokyo.

Autor, 2005. 


\section{CONCLUSÃO}

Manifesto acordo com Quin (2002) quando ele escreve que "é óbvio que há necessidade de gestão urbana nas cidades Japonesas", mas os resultados têm sido escassos, se analisados numa perspectiva internacional. De acordo com uma sondagem de opinião mencionada por Seta (2008), no geral os Japoneses apoiam actividades de revitalização urbana, em vez da expansão para a periferia, mas as realidades vividas parecem ser algo diferentes.

Bi-Matsui (2009) refere que cerca de dois terços das TMO em operação tinha, em 2006, como principal objectivo desenvolver acções de promoção das áreas comerciais. Mais de metade não tinha empregados a tempo inteiro. O grande número de proprietários de estabelecimentos comerciais tornava habitualmente difícil a obtenção de consensos e o estabelecimento de prioridades para a revitalização urbana.

Por sua vez, Miyazawa (2006) defende que as contribuições das TMO têm sido mínimas e limitadas a eventos promocionais, com poucos melhoramentos urbanos. Da literatura consultada podem extrair-se algumas ideias essenciais: 1) necessidade de encontrar elementos externos distintivos, 2) contastação do domínio da TMO por algum comerciante ficando limitada a voz dos restantes participantes, 3) reprodução de estratégias de outros lugares sem incorporação das especificidades locais 4) dificuldades para angariar financiamentos adicionais, e 5) incapacidade para ultrapassar a dependência económica de subsídios públicos.

É sabido que a resiliência do sistema comercial (Salgueiro e Cachinho, 2011) está nas pessoas e nas suas relações de confiança enquanto membros de uma comunidade a várias escalas: local, regional, nacional e internacional. Mas os governos locais têm um papel importante no estímulo ao desenvolvimento urbanístico equilibrado, que permita que os consumidores em desvantagem tenham condições equitativas de acesso a bens de primeira necessidade. Por exemplo, devem ter um papel importante no planeamento do uso do solo e no planeamento das acessibilidades e transportes, assim como na localização e na minimização do impacto das novas áreas comerciais sobre as áreas centrais das cidades (Park, 2004; Takami, 2006; Shen et al., 2011).

$\mathrm{O}$ argumento principal é que as tendências de adopção de mecanismos e boas práticas estrangeiras têm-se mostrado algo inadequadas, devido sobretudo à ineficácia da articulação dos poderes públicos com a sociedade civil. Sem um modo de institucionalizar os procedimentos colaborativos, as parcerias público-privadas mostram-se limitadas para a continuação e eficácia de acções de revitalização e gestão urbana. A falta de recursos tais como financiamentos e conhecimentos técnicos não parecem ser o problema principal. Contudo, a sua ligação a mecanismos que envolvem colaborações entre os vários níveis da administração pública e da sociedade civil pode reduzir as possibilidades de acção.

Por outro lado, a diferença de interesses e prioridades entre atores públicos e privados no estabelecimento e na manutenção das operações de gestão urbana pode dificultar a sua viabilidade no longo prazo. Um modo de tornar as acções de revita- 
lização mais efectivas é gerar confiança entre os membros das TMO (Gima, 2010). Isto requer passar de conhecimentos tácitos individuais a conhecimentos explícitos colectivos. Para além desta tarefa, é também necessário ter em conta características das cidades, tais como geografia, demografia, base cultural, industrial e comercial, entre outras.

\section{AGRADECIMENTOS}

O autor agradece os comentários dos dois referees, assim como a minuciosa revisão editorial do texto realizada pela Revista Finisterra.

\section{BIBLIOGRAFIA}

Abe H (1999) The impact of out-of-town shopping center on shopping behavior: a case study of Okayama City. Actas do $5^{\circ}$ Congresso Internacional da APSA, 8-10 Set. Seoul, Coreia do Sul: $1-20$.

Alden J (1984) Metropolitan planning in Japan. Town Planning Review, 55(1): 55-74.

Azuma N, Fernie J (2001) Retail marketing strategies and logistical operations at a Japanese grocery supermarket chain - case study of Summit Inc. International Journal of Retail and Distribution Management, 29(6/7): 284-299.

Balsas C (2008) Commercial urbanism in Phoenix, a brief study of four retail formats in Arizona. Actas do II CinCci-International Colloquium on Commerce and City. Universidade de São Paulo, FAU/USP, Brasil, 17-19 Março [CD].

Balsas C (2005) An introduction to sustainable urban regeneration. Atas do $1^{\text {st }}$ Symposium on Sustainable Urban Regeneration in Japan and Phoenix, Arizona State University (ASU), Tempe, AZ, 26 de Maio: 1-30.

Barata-Salgueiro T, Cachinho H (Ed.) (2011) Retail Planning for the Resilient City. Consumption and Urban Regeneration. CEG, Lisboa.

Salgueiro TB, Magalhães P (2005) Sol Nascente. Música no álbum Obrigada. EMI Música Portugal.

Beniya S (s/d) The commercial revival of disaster-hit areas by town management organization. Manuscrito na posse do autor.

Bi-Matsui T (2009) Consensus building in shopping district associations and downtown commercial re-vitalization in Japan. Berkeley Planning Journal, 22: 71-82.
Caballero J, Tsukamoto Y (2009) Tóquio public space networks at the intersection of the commercial and the domestic realms (Part III) Study of transit centers. Journal of Asian Architecture and Building Engineering, 6(1): 468-468.

Carmona M (2012) Designing the Japanese city part 2: A collective neglect. Town and Country Planning, 81(6): 296-301.

Castells M (1996) The rise of the network society. Vol.1. Blackwell, Oxford.

Cybriwsky R (1993) Tóquio. Cities, 10(1): 2-11.

Devezas T, Rodrigues J (2007) Portugal - O Pioneiro da Globalização. Edições Centro Atlântico, Vila Nova de Famalicão.

Evans N (2002) Machi-zukuri as a new paradigm in Japanese urban planning: Reality or myth? Japan Forum, 14(3): 443-464.

Flath D (1988) Why are there so many retail stores in Japan? Working papers. Center on Japanese Economy and Business. Columbia University. http://academiccommons.columbia. edu/item/ac:108217 (Acedido em 21 de Novembro, 2014).

Garon S, Maclachlan L (2006) The ambivalent consumer: questioning consumption in East Asia and the West. Cornell University Press, Ithaca.

Gima T (2010) Possibility of activating the City's Central Commercial Business. reposit.sun. ac.jp/dspace/bitstream/10561/744/1/ v43n4p51_gima.pdf (Acedido em 7 de Outubro, 2012).

Greenbie B (1988) Space and spirit in modern Japan. New Haven, Yale University Press. 
Grier J (2001) Japan's regulation of large retail stores: Political demands versus economic interests. U. PA. J. INT'L L., 22(1): 1-60.

Gruen V (1964) The heart of our cities: the urban crisis, diagnosis and care. Reinhold, Nova Iorque.

Haghirian P, Toussaint A (2011) Japanese Consumer Behavior. In Haghirian P (ed.) Japanese Consumer Dynamics. Palgrave Macmillan, Chippenham: 18-30.

Hall P (1998) Cities in civilization. Fromm International, Nova Iorque.

Hattori K (2011) Shimokitazawa, the study of organically developed shopping district in Tóquio. Actas do Congresso Mundial das Escolas de Planeamento (WPSC). Perth, Austrália, 4-8 de Julho.

Japan Times (2007) Editorial: New Hearts for Dying Cities. Japan Times. 20 de Fevereiro. http:// www.japantimes.co.jp/ text/ed20070220a1. html (Acedido em 7 de Outubro, 2012).

JETRO (2009) Attractive Sectors - Retail, Abril 2009. www.investjapan.org (Acedido em 5 de Outubro, 2012).

JETRO (2004) Japanese Market Report. Retail Business. No.72; Março.

JETRO (2000) Japanese Market Report, Regulations and Practices. Retail Business. No.48 Novembro.

JIJI Press (2011) Japan eyes greater private-sector role in urban regeneration. JIJI - Financial Times, 4 de Janeiro.

Kidokoro T (2004) Regeneration of Cities as Commons. Actas do International Workshop on Asian Approach towards Sustainable Urban Regeneration. Tóquio, Japão, 4-7 de Setembro.

Kobayashi Y (2005) Japan vs. Phoenix. $1^{\text {st }}$ Symposium on Sustainable Urban Regeneration in Japan and Phoenix, Arizona State University (ASU), Tempe, AZ, 26 de Maio.

Koizumi H (2004) Empowerment in the Japanese Planning Context. In Sorensen A, Marcotullio P, Gran J (eds.) Towards Sustainable Cities; East Asian, North American and European Perspectives on Managing Urban Regions. Ashgate, Burlington: 217-227.

Kyogoku R (2006) Can revised laws revive languishing city centers? The Yomiuri Shimbun, 21 de Janeiro.

Marcotullio P (2004) Why the Asian Urbanization Experience Should Make Us Think
Differently about Planning Approaches. In Sorensen A, Marcotullio P, Grant J (eds.) Towards Sustainable Cities; East Asian, North American and European Perspectives on Managing Urban Regions. Ashgate, Burlington: 38-58.

Matsui K, Lu S, Nariu T, Yukimoto T (2005) Marketing channels and retail store density in East Asia. Asian Economic Journal, 19(4): 407-422.

Matsushita K (2001) Depato. In Chung C, Inaba J, Koolhaas R, Leong T (eds.) Harvard Design School Guide to Shopping. Taschen, Nova Iorque: 243-269.

Miyazawa M (2006) Downtown Revitalization in Japan: Examination of the Town Management Organization Model. Dissertação de Mestrado. Cambridge, MA: Department of Urban Studies and Planning, Massachusetts Institute of Technology, Boston.

Muraki M (2003) Town centre revitalization in Japan, relationship between Town Centre and Out-of-Centre developments. Actas do Congresso da APSA em Hanói, 12-14 Setembro.

Murayama A (2005) Sustainable urban regeneration in Tóquio. $1^{\text {st }}$ Symposium on Sustainable Urban Regeneration in Japan and Phoenix, Arizona State University (ASU), Tempe, AZ, 26 de Maio.

Nashima M (1997) Old-style shopping areas fight to survive. Japan Times, Agosto 13. http://www.japantimes.co.jp/news/1997/08/ 13/national/old-style-shopping-areas-fight-to-survive/\#.U1C-G_ldV8k (Acedido em 7 de Outubro, 2012).

Onishi Y (1994) Urban commercial redevelopment in Japan and its evaluation. Journal of Retailing and Consumer Services, 1(2): 107-112.

Park C (2004) Lessons of downtown revitalization plans in Korea. Urban Policy and Research, 22(4): 447-463.

Quin S (2002) Japan's Town Centres Struggle in Absence of UK Style Policies. Urban Environment Today, 16 Maio: 12.

Sassen S (2001) The Global City: Nova Iorque, Londres, Tóquio. Princeton University Press, Princeton.

Seta F (2008) Activities of Local Organizations for Downtown Revitalization in Regional Cities. In Kidokoro T, Harata N, Subanu L, Jessen J, Motte A, Seltzer E (eds.) Sustainable City 
Regions: Space, Place and Governance. Urban Regeneration and Local Governance in Regional Cities. Springer, Nova Iorque: 163-181.

Shelton B (1999) Learning from the Japanese City, West meets East in urban design. E\&F Spon, Londres.

Shen Z, Yao X, Kawakami M, Chen P (2011) Simulating spatial market share patterns for impacts analysis of large-scale shopping centers on downtown revitalization. Environment and Planning B, 38: 142-162.

Shibata K (2008) Neoliberalism, risk and spatial governance in the developmental state: Japanese planning in the global economy. Critical Planning, 15: 93-118.

Sorensen A (2009) Neighborhood streets as meaningful spaces: Claiming Rights to Shared Spaces in Tóquio. City and Society, 21(2): 207-229.

Sorensen A (2004) Major Issues of Land Management for Sustainable Urban Regions in Japan. In Sorensen, A, Marcotullio P, Grant J (eds.) Towards Sustainable Cities, East Asian, North American and European Perspectives on Managing Urban Regions. Ashgate, Burlington: 198-216.

Sorensen A (2002) The Making of Urban Japan. Routledge, Nova Iorque.

Sorensen A, Marcotullio P, Grant J (2004) Towards Sustainable Cities, East Asian, North Ame- rican and European Perspectives on Managing Urban Regions. Ashgate, Burlington.

Sorensen A, Koizumi H, Miyamoto A (2009) Machizukuri, civil society, and community space in Japan. In Daniere A, Douglas M (eds.) The politics of civic space in Asia - building urban communities. Routledge, Nova Iorque: 33-50.

Sulkin S (2003) Japanese retail development begins to show signs of life. Shopping Centers Today, Asia-Pacific, Julho. http://www.icsc. org $/ \mathrm{srch} / \mathrm{sctA} / 1 \mathrm{a} . \mathrm{htm}$ (Acedido em 7 de Outubro, 2012).

Takami K (2006) Car use and sustainability, reflection on retail development control systems. In Tamagawa H (ed.) Sustainable Cities, Japanese Perspectives on Physical and Social Structures. United Nations University Press, Tóquio: 139-166.

The Yomiuri Shimbun (2012) Assist 'Disadvantaged shoppers,' revitalize local economies. The Yomiuri Shimbun. 25 de Junho. http://www. yomiuri.co.jp/dy/editorial/T120625004433. htm (Acedido em 7 de Outubro, 2012).

Upham F (1993) Privatizing regulation: the implementation of the large-scale retail stores law. In Allinson G, Sone Y (eds.) Dynamics in Comptemporary Japan. Cornell University Press, Ithaca: 264-294.

Yamashita M (2004) Decline and approaches to revitalization in small cities: the case of Saga: Japan. Dela, 21: 461-473.

i Study Group on the Role of Distribution Systems in Community Infrastructure. (2010: 36) Relatório "Distribution Systems in the Context of Local Communities".

ii De acordo com Kidokoro (2004), uma cidade regional no Japão tem desde 300 mil a 1 milhão de habitantes.

iii Nomeadamente em Janeiro de 2005 e Janeiro de 2007. As visitas técnicas e reuniões de trabalho tiveram lugar em Tóquio no empreendimento imobiliário Shiodome e no TMO Center-Gai em Shibuya, e no TMO Sakura na prefeitura de Chiba.

iv Por exemplo de $64 \mathrm{~m}^{2}$ em 1988 para $127 \mathrm{~m}^{2}$ em 2002, um aumento de cerca do dobro (JETRO, 2004: 4).

v De acordo com Flath (1988: 1), em 1982 existiam 145,3 estabelecimentos comerciais por cada 10 mil pessoas no Japão, enquanto nos EUA, Reino Unido, França e Alemanha Ocidental este indicador era de apenas $82,9,62,7,74,8$, e 67,0 respectivamente.

vi Estas três cadeias comerciais [i.e. OfficeMax Japan (US), Sephora AAP Japan (France) wholly owned (LVMH Group), e The Boots (UK) Mitsubishi] entraram em 1997 e sairam fugazmente em 2001. 
vii De acordo com a Associação Japonesa de Centros Comerciais (JCSC), um centro comercial no Japão é definido como um empreendimento de negócios e serviços devidamente planeado, construído e gerido por uma dada entidade - na maioria dos casos com uma função urbana e com estacionamento próprio - que satisfaz as necessidades dos residentes de um modo apropriado, conveniente e aprazível, dependendo da sua localização, escala e composição.

viii Tradução do autor.

ix Estas dimensões, aparentemente reduzidas quando comparadas com o dimensionamento médio dos estabelecimentos comerciais em Portugal, têm a ver com o elevado custo do solo urbano e peri-urbano.

x Matsui et al. (2005: 416) atribuem o declínio do número de estabelecimentos comerciais ao aumento da taxa de motorização (78.9\% de 1982 a 1997) e ao aumento dos edifícios habitacionais. 